\title{
Composite valve graft implantation for the treatment of aortic valve and root disease: Results in 1045 patients
}

Luca Di Marco, MD, PhD, Davide Pacini, MD, PhD, Antonio Pantaleo, MD, Alessandro Leone, MD, Giuseppe Barberio, MD, Giuseppe Marinelli, MD, and Roberto Di Bartolomeo, MD

\section{ABSTRACT}

Objectives: Aortic root replacement using a composite graft is the treatment of choice for a large variety of aortic root conditions with a diseased aortic valve. The objective of the current study was to evaluate the long-term results of this procedure.

Methods: Between 1978 and 2010, 1045 patients aged $58.7 \pm 13.6$ years underwent aortic root composite graft replacement using the following techniques: 95 Bentall operation; 926 the "button technique;" 24 the Cabrol technique. A mechanical composite valve graft was implanted in $69.6 \%$ of the patients. Sixhundred and thirty-five patients $(62.3 \%)$ had annuloaortic ectasia and 162 $(15.5 \%)$ had aortic dissection.

Results: Early mortality was 5.3\% (55/1045). Independent risk factors for early mortality at logistic regression analysis were age $\geq 70$ years $(P=.051$; odds ratio [OR], 2.97), New York Heart Association III-IV $(P=.052 ;$ OR, 1.88), reoperation $(P=.021 ;$ OR, 2.36), urgency/emergency $(P=.003 ;$ OR, 3.09), mitral valve replacement $(P=.001$; OR, 6.01), or coronary artery bypass grafting (CABG) $(P<.001$; OR, 4.39); while bicuspid aortic valve (BAV) $(P=.013$; OR, 0.21), and time of operation 2001-2011 ( $P=.025$; OR, 0.60) were protective predictors for early mortality. Overall survival at 5, 10, and 20 years was $84.1 \% \pm 1.3 \%$, $65.5 \% \pm 2.6 \%$, and $40.7 \% \pm 4.6 \%$, respectively. Multivariate analysis revealed chronic renal insufficiency $(P=.001$; hazard ratio [HR], 3.48), chronic obstructive pulmonary disease $(P=.027 ; \mathrm{HR}, 1.94)$, aortic dissection $(P=.001 ; \mathrm{HR}, 2.63)$, Cabrol technique $(P=.009 ; \mathrm{HR}, 15.34)$, and CABG $(P=.016 ; \mathrm{HR}, 2.02)$ to be significant predictors of late death, and $\operatorname{BAV}(P=.010 ; \mathrm{HR}, 0.43)$ to be a significant protective predictor. Freedom from thromboembolism, bleeding complications, and endocarditis was $93.7 \% \pm 2.6 \%, 90.3 \% \pm 3.1 \%$, and $98.4 \% \pm 1 \%$ at 20 years, respectively. Freedom from aortic reoperation was $91.8 \% \pm 2.1 \%$ at 20 years and was significantly lower in patients with aortic dissection.

Conclusions: Within the limitations of this retrospective study, we can conclude that aortic root replacement for aortic root aneurysms can be performed with low morbidity and mortality and with satisfactory long-term results. Few late serious complications were related to the need for long-term anticoagulation or a prosthetic valve. Reoperation on the proximal or in the distal aorta was most commonly performed in patients with aortic dissection. ( $\mathrm{J}$ Thorac Cardiovasc Surg 2016;152:1041-8)

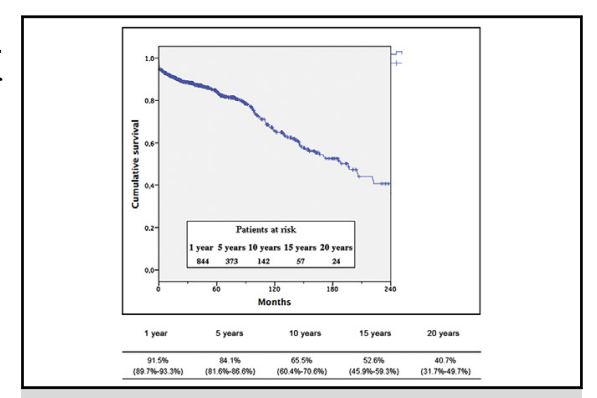

Survival rates (including hospital mortality) of the 1045 patients.

\section{Central Message}

Aortic root replacement with a composite valve graft provides good early and long-term results.

\section{Perspective}

This study reports the experience of 33 years of treatment of aortic root disease using a composite valve graft. The high number of patients included and the long period of follow-up make it the largest series to be published. Composite valve graft implantation can be performed with low morbidity and mortality, and with satisfactory long-term results.

See Editorial Commentary page 1049.

See Editorial page 956.
Aortic root replacement using a composite valve graft (CVG) is the treatment of choice for a diseased aortic valve and root dilatation. First described by Hugh Bentall and

\footnotetext{
Cardiac Surgery Department, S. Orsola-Malpighi Hospital, University of Bologna, Bologna, Italy.

L.D.M. and D.P. contributed equally to the paper.

Received for publication Nov 14, 2015; revisions received April 20, 2016; accepted for publication May 20, 2016; available ahead of print June 14, 2016
}

Anthony De Bono in $1968,{ }^{1}$ it is a widely used procedure for combined aortic valve and ascending aorta disease, including lesions associated with type A acute aortic

\footnotetext{
Address for reprints: Luca Di Marco, MD, PhD, Cardiac Surgery Department, S Orsola-Malpighi Hospital, University of Bologna, via Massarenti 9, 40138 Bologna, Italy (E-mail: ludima08@libero.it). $0022-5223 / \$ 36.00$

Copyright (C) 2016 by The American Association for Thoracic Surgery http://dx.doi.org/10.1016/j.jtcvs.2016.05.021
} 


\section{Abbreviations and Acronyms}

AMI = acute myocardial infarction

$\mathrm{BAV}=$ bicuspid aortic valve

$\mathrm{B}-\mathrm{CVG}=$ biological composite valve graft

DHCA $=$ deep hypothermia with circulatory arrest

$\mathrm{M}-\mathrm{CVG}=$ mechanical composite valve graft

NYHA $=$ New York Heart Association

$\mathrm{RF} \quad=$ radiofrequency

Scanning this QR code will take you to the appendix for this article.

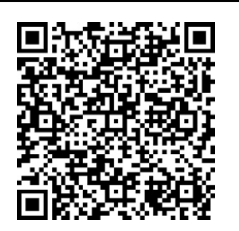

dissection and Marfan syndrome. However, despite its proven outcome and the good results obtained by experienced surgeons, ${ }^{1-3}$ aortic root replacement using a composite graft also exposes patients to the problems associated with prosthetic valves, such as life-long anticoagulation for the mechanical prosthesis, structural valve deterioration for the biological prosthesis, and the increased risk of thromboembolism and endocarditis for both. In the present retrospective study we have evaluated the results of our 33-year's experience with 1045 patients with aortic root replacement using a CVG.

\section{METHODS \\ Patients}

Between 1978 and December 2010, 1045 patients aged $58.7 \pm 13.6$ years underwent aortic root replacement using a CVG. Eight hundred and thirty-four patients $(79.8 \%)$ were men and 211 were women $(20.2 \%)$. Patient characteristics are shown in Table 1. In most patients, the indication for the CVG procedure was annuloaortic ectasia (635 patients [62.3\%]) and aortic dissection (162 patients [15.5\%]). One hundred and twenty-seven (12.2\%) were redo operations, whereas 14 patients $(1.3 \%)$ had previously undergone more than one aortic surgery. Nine hundred and thirty patients $(89 \%)$ were operated on electively. Detailed surgical indications are shown in Table 2.

The study protocol conforms to the ethical guidelines of the 1975 Declaration of Helsinki as reflected in a priori approval by the institute's human research committee and was approved by the Ethics Committee of Bologna Medical University.

All patient data were entered into a patient dataset; approval to conduct this retrospective study without individual patient consent was provided by our institutional review board.

\section{Operative Technique}

The operative technique has previously been described in detail. ${ }^{3}$

Briefly, a standard median sternotomy was performed and cardiopulmonary bypass was instituted by cannulation of the ascending aorta, aortic arch, femoral or axillary artery, or brachiocephalic trunk, depending on the extension of the aneurysm and the presence of dissection, and the right atrium or the superior and inferior vena cavae. Myocardial protection was achieved with cold crystalloid cardioplegia and topical cooling with $4^{\circ} \mathrm{C}$ saline solution. The first 95 patients $(9.1 \%)$ underwent the classic Bentall operation, ${ }^{1}$ with the inclusion and wrapping technique. In 1994 we abandoned the classic Bentall operation and started using the button technique, ${ }^{4,5}$ a modification of the original technique. ${ }^{1,6}$ Since 1994, 926 patients $(88.6 \%)$ have undergone aortic root and valve replacement with CVG according to the modified Bentall procedure, 24 (2.3\%) underwent the Cabrol technique ${ }^{7}$ in the case of difficult coronary mobilization, such as extreme aortic dilatation or reoperation. Since 2000 we have been using biological CVG (B-CVG); initially homemade by combining a biological valve prosthesis with the tube graft and then using a composite graft prosthesis. A biological valve was chosen over a mechanical valve on the basis of patient age; patients older than 65 years and those with contraindications to anticoagulation were usually advised to opt for a biological valve. Patients younger than 60 years of age usually received a mechanical valve unless they were adversely affected by anticoagulation therapy. Some younger patients preferred a biological valve despite understanding that this would lead eventually to a second operation. Patients with a biological valve were advised to take warfarin daily only for the first 3 months and then to continue with aspirin. All patients with mechanical valves were treated with warfarin, with a target international normalized ratio of 2.0 to 3.0 .

Three hundred and eighteen patients $(30.4 \%)$ received a B-CVG, and 727 patients $(69.6 \%)$ had a mechanical valve conduit inserted. Concomitant procedures included coronary artery bypass grafting (CABG) in 119 patients $(11.4 \%)$, mitral valve replacement in 37 (3.5), and mitral valve repair in $8(0.8 \%)$. We performed atrial fibrillation radiofrequency (RF) ablation in 39 individuals (3.7\%). In the event of concomitant arch surgery, cerebral protection was obtained with deep hypothermia with circulatory arrest (DHCA) in 15 patients, DHCA and retrograde cerebral perfusion in 1 , and antegrade selective cerebral perfusion with moderate systemic hypothermia in $158 .{ }^{8}$ In $3.7 \%$ of the patients, we performed atrial fibrillation bipolar RF ablation using 2 different systems over 2 different periods. In the first period, we used the Cobra Bipolar system (Boston Scientific, San Josè, Calif) but in recent years we have used the Cardioablate BP (Medtronic, Minneapolis, Minn). Operative data and procedures are shown in Table 3.

\section{Follow-up}

Of all hospital survivors (990 patients), 966 (97.6\%) were available and 24 were lost to follow-up. The mean follow-up time was $62.1 \pm 58.6$ months (ranging from 3 months to 380.4 months). Followup information was obtained by direct telephone interview with the patient or with a close relative, by contact with the referring physician, or by a visit to our outpatient clinic.

\section{Statistical Analysis}

Statistical analysis was carried out with SPSS 20.0 statistical software (SPSS, Chicago, Ill). Continuous variables were expressed as the mean $\pm \mathrm{SD}$ and were compared with the unpaired two-tailed $t$ test. Categorical variables were analyzed with a $\chi^{2}$ test or Fisher exact test where appropriate. All variables that achieved a $P$ value less than .2 in the univariate analysis were included in a multivariate analysis and examined by stepwise logistic regression for early mortality, and Cox multivariate analysis for late mortality. Survival and event-free data were analyzed with Kaplan-Meier actuarial techniques for estimation of survival probabilities and compared with log rank tests.

Statistical significance was considered at $P<.05$.

\section{RESULTS}

\section{Early Mortality}

Early mortality or in-hospital mortality was defined as death within 30 days or during initial hospitalization. In 
TABLE 1. Patient characteristics and risk factors

\begin{tabular}{|c|c|c|}
\hline & Number of patients & $\%$ \\
\hline Number of patients & 1045 & - \\
\hline \multicolumn{3}{|l|}{ Gender } \\
\hline Male & 834 & 79.8 \\
\hline Female & 211 & 20.2 \\
\hline Age $(y)$, mean \pm SD & $58.7 \pm 13.6$ & \\
\hline \multicolumn{3}{|l|}{ NYHA class } \\
\hline I & 275 & 26.3 \\
\hline II & 411 & 39 \\
\hline III & 284 & 27.1 \\
\hline IV & 75 & 7.1 \\
\hline Hypertension & 686 & 65.6 \\
\hline History of smoking & 492 & 47.1 \\
\hline Diabetes & 148 & 14.2 \\
\hline Hypercholesterolemia & 336 & 32.2 \\
\hline Chronic renal insufficiency & 33 & 3.2 \\
\hline Coronary artery disease & 143 & 13.7 \\
\hline COPD & 89 & 8.5 \\
\hline Previous CVA & 49 & 4.7 \\
\hline Marfan syndrome & 55 & 5.3 \\
\hline Bicuspid aortic valve & 311 & 29.8 \\
\hline \multicolumn{3}{|l|}{ Operative periods } \\
\hline $1978-1990$ & 76 & 7.3 \\
\hline $1991-2000$ & 188 & 18 \\
\hline $2001-2010$ & 781 & 74.7 \\
\hline
\end{tabular}

$S D$, Standard deviation; NYHA, New York Heart Association; COPD, chronic obstructive pulmonary disease; $C V A$, cerebrovascular accident.

the overall population it was $5.3 \%$ (55 of 1045 patients), without significant differences between patients who received B-CVG or mechanical CVG (M-CVG) $(6 \%$ [19/318 patients] vs 5\% [36/727 patients], respectively; $P=.49)$. Causes of death are shown in Table 4.

Patients operated on an elective regimen had a mortality rate of $4.4 \%$, whereas for emergent/urgent patients, the rate was $12 \%$. In-hospital mortality was $11.1 \%$ and $4.2 \%$ in patients with and without aortic dissection, respectively $(P<.001)$. Even patients with a previous cardiovascular operations had a higher mortality rate $(9.4 \%$ vs $4.7 \%)$. Table 5 shows the univariate and multivariate analyses for early mortality. In the multivariate analysis, independent risk factors for early mortality were New York Heart Association (NYHA) III-IV, reoperation, urgency/emergency, mitral valve replacement, or CABG, whereas bicuspid aortic valve (BAV) and time of operation 2001-2011 were protective predictors for early mortality.

\section{Early Morbidity}

Postoperative complications are shown in Table 6. The main neurologic complications were psychomotory agitation in 30 patients, stroke and temporary ischemic attack in 13 , tonico-clonic seizures in 12 , coma in 5 , paraplegia in 3 , paraparesis in 2 , and cerebral hemorrhage in 2 . Of patients who had pulmonary complications, 19 required prolonged mechanical ventilation (more than 48 hours).
TABLE 2. Surgical indications

\begin{tabular}{lcc}
\hline & $\begin{array}{c}\text { Number of } \\
\text { patients }\end{array}$ & \begin{tabular}{c}
$\%$ \\
\hline Primary operation
\end{tabular} \\
Annuloaortic ectasia & 618 & 87.8 \\
Aortic dissection & 635 & 69.1 \\
$\quad$ Acute & 88 & 11.4 \\
Chronic & 17 & 83.8 \\
Post-stenotic dilatation & 165 & 16.2 \\
Endocarditis & 12 & 18 \\
Reoperation & 127 & 1.3 \\
Aortic valve prosthesis endocarditis & 12 & 9.4 \\
Valsalva sinus aneurysm after AVR or AAR & 52 & 40.9 \\
Aortic dissection & 57 & 44.9 \\
$\quad$ Acute & 5 & 8.8 \\
Chronic & 52 & 91.2 \\
False aneurysm & 4 & 3.1 \\
Mechanical prosthetic valve dysfunction & 2 & 1.6 \\
\hline$A V R$, Aortic valve replacement; $A A R$, ascending aorta replacement. &
\end{tabular}

\section{Late Mortality}

During follow-up, there were 164 late deaths $(16.6 \%)$. The main causes were tumor, sudden death, and stroke.

Multivariate analysis and statistically significant predictors for late mortality are shown in Table 7.

The overall survival of the 1045 patients is shown in Figure 1 . The survival rate at $1,5,10,15$, and 20 years

TABLE 3. Operative procedures and data

\begin{tabular}{lcc}
\hline & $\begin{array}{c}\text { Number of } \\
\text { patients }\end{array}$ & $\%$ \\
\hline Elective status & 930 & 89 \\
Urgent/emergent status & 115 & 11 \\
Modified Bentall & 926 & 88.6 \\
Classic Bentall & 95 & 9.1 \\
Cabrol technique & 24 & 2.3 \\
Mechanical CVG & 727 & 69.6 \\
Biological CVG & 318 & 30.4 \\
Associated procedures & & \\
Coronary artery bypass grafting & 119 & 11.4 \\
Mitral valve replacement & 37 & 3.5 \\
Mitral valve repair & 8 & 0.8 \\
Tricuspid valve repair & 8 & 0.8 \\
AF ablation & 39 & 3.7 \\
Hemiarch replacement & 74 & 7.1 \\
Arch replacement & 76 & 7.3 \\
Arch + ET & 12 & 1.1 \\
Arch + FET & 12 & 1.1 \\
Cardiopulmonary bypass time (min), & $156 \pm 56.5$ & \\
mean \pm SD & & \\
Aortic cross-clamp time (min), mean \pm SD & $118 \pm 35.5$ & \\
ASCP & 158 & 15.1 \\
RCP & 1 & 0.1 \\
DHCA & 15 & 1.4 \\
\hline$C V G$ Co
\end{tabular}

$C V G$, Composite valve graft; $A F$, atrial fibrillation; $E T$, elephant trunk; $F E T$, frozen elephant trunk; $S D$, standard deviation; $A S C P$, antegrade selective cerebral perfusion; $R C P$, retrograde cerebral perfusion; $D H C A$, deep hypothermic circulatory arrest. 
TABLE 4. Causes of death

\begin{tabular}{lccc}
\hline & $\begin{array}{c}\text { Number of } \\
\text { patients (\%) }\end{array}$ & $\begin{array}{c}\text { Mechanical } \\
\text { Bentall (n) }\end{array}$ & $\begin{array}{c}\text { Biological } \\
\text { Bentall (n) }\end{array}$ \\
\hline Cardiac & $28(51)$ & 9 & 19 \\
MOF & $14(25.5)$ & 6 & 8 \\
Respiratory & $4(7.3)$ & 2 & 2 \\
Sepsis & $3(5.4)$ & 2 & 1 \\
Uncontrollable bleeding & $3(5.4)$ & - & 3 \\
Neurologic & $2(3.6)$ & - & 2 \\
Gastrointestinal & $1(1.8)$ & - & 1 \\
\hline
\end{tabular}

$M O F$, Multi-organ failure.

was $91.5 \% \pm 0.9 \%, 84.1 \% \pm 1.3 \%, 65.5 \% \pm 2.6 \%$, $52.6 \% \pm 3.4 \%$, and $40.7 \% \pm 4.6 \%$, respectively.

Patients with aortic dissection had lower survival rates compared with those without aortic dissection $(55.7 \%$ vs $67.4 \%, 39.7 \%$ vs $55.1 \%$, and $27.2 \%$ vs $43.3 \%$ at 10,15 , and 20 years, respectively) and the difference was significant $(P<.01$; Figure 2$)$.

\section{Late Morbidity}

At the last follow-up, $542(542 / 802,67.6 \%)$ of the surviving patients had M-CVG and 260 (260/802, 32.4\%) had B-CVG. Five hundred and eighty-six patients (586/ $802,73.1 \%$ ) were receiving warfarin (Coumadin): 542 $(100 \%)$ with M-CVG and $44(44 / 260,17 \%)$ with B-CVG.

Three hundred and thirty-one patients $(331 / 802,41.2 \%)$ were in NYHA functional class I, $369(369 / 802,46 \%)$ in NYHA functional class II, $95(95 / 802,11.9 \%)$ in NYHA functional class III, and $7(7 / 802,0.9 \%)$ in NYHA IV. Data on freedom from thromboembolic events, aortic reoperations, oral anticoagulation therapy-related hemorrhagic events, and prosthetic endocarditis are shown in Table 8.

\section{DISCUSSION}

The CVG procedure according to the modified Bentall technique is currently considered to be the gold standard for the treatment of ascending aorta aneurysm or type A aortic dissection with a diseased and irreparable aortic valve. Although the CVG procedure exposes patients to the problems associated with artificial valves, it remains the treatment of choice for aortic root disease.

The results obtained with this technique are excellent and are strongly associated with the underlying pathology and the patient's preoperative condition. In our experience, the independent risk factors for early mortality were age $\geq 70$ years (OR, 2.97), NYHA III-IV (OR, 1.88), reoperation (OR, 2.36), urgency/emergency (OR, 3.09), mitral valve replacement (OR, 6.01), and CABG (OR, 4.39). Preoperative BAV has proven to be a protective factor for both early and late mortality. This could be explained by the fact that patients with BAV are usually younger and therefore have fewer comorbidities compared with other patients. In our series, the mean age of patients with BAV was $55.4 \pm 13.7$ years; the mean age of the rest of the population was $60.1 \pm 13.4$ years $(P=.01)$. The overall early mortality was $5.3 \%$. This was reduced to $4.4 \%$ in patients operated on electively, whereas for patients who had emergency surgery it was $12 \%$. Patients with a preoperative diagnosis of aortic dissection $(n=162)$ had a mortality rate of $11.1 \%$; for those with a different preoperative diagnosis, the mortality rate was $4.2 \%$. Patient age $\geq 70$ years negatively influenced the early mortality. The mortality rate of patients older and younger than 70 years was $9.5 \%$ and $4.3 \%$, respectively; that of patients in NYHA class III-IV and NYHA class I-II was $9.5 \%$ and $3.1 \%$, respectively. As expected, the most frequent cause of death was cardiac, and it was more frequent in patients who underwent aortic root

TABLE 5. Univariate and multivariate analysis for early mortality

\begin{tabular}{|c|c|c|c|c|c|c|}
\hline & \multicolumn{3}{|c|}{ Unadjusted OR } & \multicolumn{3}{|c|}{ Adjusted OR } \\
\hline & OR & $95 \% \mathrm{CI}$ & $\boldsymbol{P}$ & OR & $95 \% \mathrm{CI}$ & $\boldsymbol{P}$ \\
\hline Age $\geq 70 y$ & 2.34 & $1.314-4.179$ & .003 & 2.97 & $1.547-5.136$ & .051 \\
\hline Preoperative NYHA III-IV & 3.19 & $1.814-5.609$ & $<.001$ & 1.875 & $0.996-3.533$ & .052 \\
\hline Chronic renal insufficiency & 3.40 & $1.261-9.189$ & .010 & & & \\
\hline COPD & 2.20 & $1.042-4.670$ & .034 & & & \\
\hline Preoperative CAD & 3.65 & $2.033-6.575$ & $<.001$ & & & \\
\hline Preoperative BAV & 0.12 & $0.039-0.407$ & $<.001$ & 0.21 & $0.063-0.717$ & .013 \\
\hline Aortic dissection & 2.85 & $1.582-5.151$ & $<.001$ & & & \\
\hline Annuloaortic ectasia & 0.41 & $0.238-0.718$ & .001 & & - & \\
\hline Reoperation & 2.10 & $1.079-4.111$ & .026 & 2.36 & $1.139-4.898$ & .021 \\
\hline Urgency/emergency & 3.01 & $1.584-5.704$ & $<.001$ & 3.09 & $1.464-6.537$ & .003 \\
\hline Time 2001-2011 & 0.45 & $0.257-0.780$ & .004 & 0.60 & $0.382-0.938$ & .025 \\
\hline Cabrol technique & 4.11 & $1.345-12.541$ & .007 & & - & \\
\hline Mitral valve replacement & 3.78 & $1.509-9.506$ & .002 & 6.01 & $2.067-17.453$ & .001 \\
\hline CABG & 3.53 & $1.907-6.545$ & $<.001$ & 4.39 & $2.187-8.795$ & $<.001$ \\
\hline
\end{tabular}

Hosmer-Lemeshow $\chi^{2}=3.005 ; \mathrm{df}=8 ; P=.934$. OR, Odds ratio; $C I$, confidence interval; $N Y H A$, New York Heart Association; $C O P D$, chronic obstructive pulmonary disease; $C A D$, coronary artery disease; $B A V$, bicuspid aortic valve; $C A B G$, coronary artery bypass grafting. 
TABLE 6. Postoperative complications

\begin{tabular}{lcr}
\hline & Number of patients & $\%$ \\
\hline Atrial fibrillation & 225 & 21.5 \\
Myocardial infarction & 28 & 2.7 \\
Complete heart block & 19 & 1.8 \\
Ventricular tachycardia/fibrillation & 18 & 1.7 \\
Cardiogenic shock & 11 & 1.1 \\
Neurologic complications & 67 & 6.4 \\
Pulmonary complications & 103 & 9.9 \\
Bleeding requiring re-thoracotomy & 48 & 4.6 \\
Renal complications & 82 & 7.8 \\
Dialysis & 47 & 4.5 \\
Temporary & 43 & 4.1 \\
Permanent & 4 & 0.3 \\
Infectious complications & 50 & 4.8 \\
\hline
\end{tabular}

replacement with a biological valve conduit. The higher cardiac mortality in this group of patients can be explained by the fact that they had a significantly higher incidence of coronary artery disease $(20.8 \%$ in B-CVG vs $10.7 \%$ in $\mathrm{M}$ CVG; $P<.001)$.

This procedure is also associated with a low incidence of early complications. Cardiac complications, which include major arrhythmias (complete heart block, ventricular tachycardia/fibrillation) and minor arrhythmias (atrial fibrillation), and acute myocardial infarction (AMI), associated or not with cardiogenic shock, vary from $11 \%$ to $15 \%$. $^{2,9}$

The most feared cardiac complication in aortic root replacement is related to the reimplantation of the coronary arteries. An incorrect coronary ostia reimplantation can cause mortality from perioperative myocardial infarction, right ventricular dysfunction, and bleeding.

Mobilization of the coronary ostia is a very important and delicate procedure requiring great care in order to prevent myocardial ischemia or pump failure.

Intraoperative and postoperative myocardial infarction has an incidence of about $5 \%$ when the surgery is carried out by an experienced physician. ${ }^{9}$ Complications of coronary reimplantation have been shown to be more frequent with the Cabrol technique. ${ }^{10-12}$ In our series, myocardial infarction occurred in 28 patients $(2.7 \%)$, and the

TABLE 7. Multivariate analysis for late mortality

\begin{tabular}{lccc}
\hline \multicolumn{1}{c}{ Variable } & HR & \multicolumn{1}{c}{ Cox regression } & \\
\cline { 3 - 3 } Chronic renal insufficiency & 3.48 & $1.714-7.079$ & .001 \\
COPD & 1.94 & $1.078-3.497$ & .027 \\
Preoperative BAV & 0.43 & $0.221-0.816$ & .010 \\
Aortic dissection & 2.63 & $1.514-4.565$ & .001 \\
Cabrol technique & 15.34 & $1.970-11.942$ & .009 \\
CABG & 2.02 & $1.139-3.572$ & .016 \\
\hline
\end{tabular}

$H R$, Hazard ratio; $C I$, confidence interval; $C O P D$, chronic obstructive pulmonary disease; $B A V$, bicuspid aortic valve; $C A B G$, coronary artery bypass grafting.

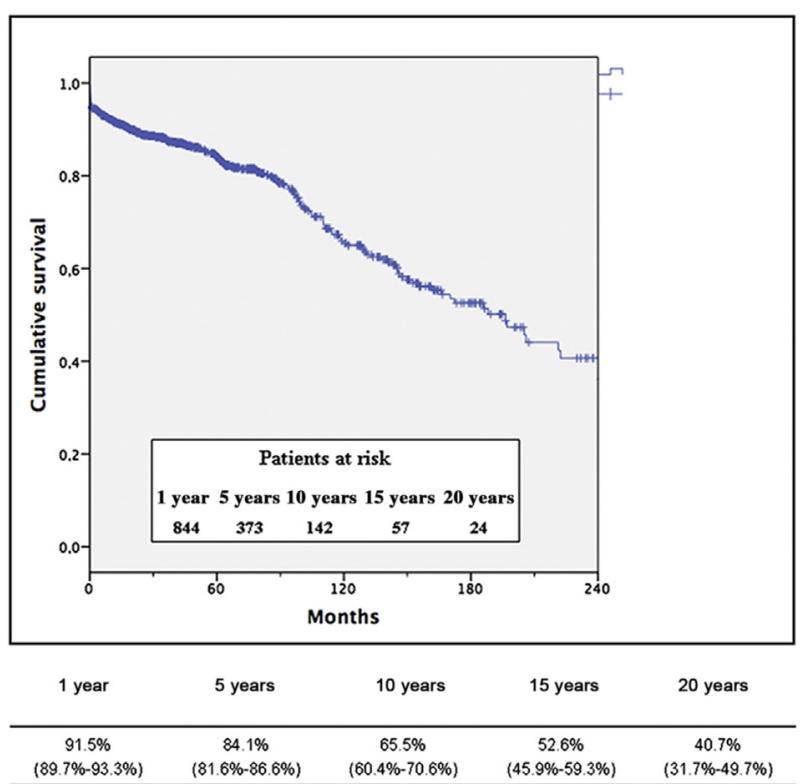

FIGURE 1. Survival rates (including hospital mortality) of the 1045 patients.

incidence was higher in patients who underwent the Cabrol technique (12.5\% [3/24] vs 2.4\% [25/1021]). This technique, although not statistically significant in the multivariate analysis, appears to be a significant risk factor for early mortality. We rarely performed $(2.3 \%)$ coronary reimplantation using the Cabrol technique; only in cases of extreme aortic dilatation because of difficult mobilization and approximation of the coronary ostia to

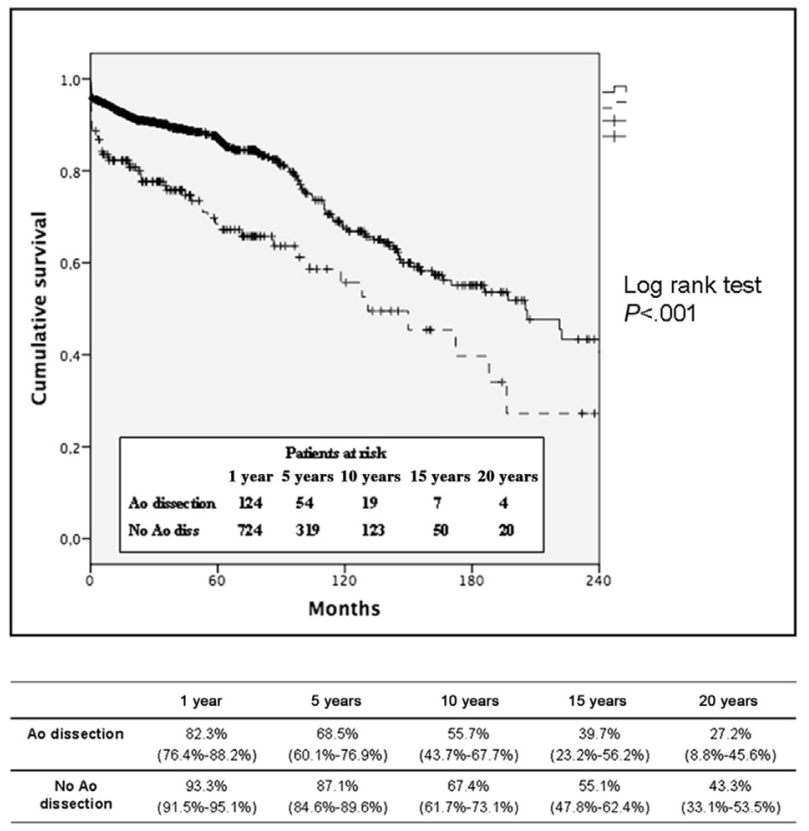

FIGURE 2. Survival rates of the patients with aortic dissection (Ao) (dashed line) and without Ao (continuous line). 
TABLE 8. Freedom from thromboembolic events, aortic reoperations, OAT-related hemorrhagic events, and endocarditis

\begin{tabular}{|c|c|c|c|c|}
\hline & $\begin{array}{c}\% \text { of patients } \\
\text { (biological) }\end{array}$ & $95 \% \mathrm{CI}$ & $\begin{array}{c}\% \text { of patients } \\
\text { (mechanical) }\end{array}$ & $95 \% \mathrm{CI}$ \\
\hline \multicolumn{5}{|c|}{ Freedom from thromboembolic events } \\
\hline $1 \mathrm{y}$ & 98.8 & $97.4-100.2$ & 99.5 & 98.9-100.1 \\
\hline $5 \mathrm{y}$ & 97 & $94.5-99.5$ & 99 & $98.2-99.8$ \\
\hline $10 \mathrm{y}$ & - & - & 97.5 & $95.5-99.5$ \\
\hline $15 \mathrm{y}$ & - & - & 96.4 & $93.5-99.3$ \\
\hline $20 \mathrm{y}$ & - & - & 90.6 & 73.4-107.8 \\
\hline \multicolumn{5}{|c|}{ Freedom from aortic reoperations } \\
\hline $1 \mathrm{y}$ & 97.7 & $95.9-99.5$ & 99.1 & 98.3-99.9 \\
\hline $5 y$ & 95.3 & $92-98.6$ & 96.4 & $94.6-98.2$ \\
\hline $10 \mathrm{y}$ & - & - & 94.2 & $91.7-96.7$ \\
\hline $15 \mathrm{y}$ & - & - & 91.7 & 87.4-96 \\
\hline $20 \mathrm{y}$ & - & - & 91.7 & 87.4-96 \\
\hline \multicolumn{5}{|c|}{ Freedom from OAT-related hemorrhagic events } \\
\hline $1 \mathrm{y}$ & 98.9 & $97.7-100.1$ & 99.4 & $98.8-100$ \\
\hline $5 \mathrm{y}$ & 97.7 & $95-100.4$ & 97.8 & $96.4-99.2$ \\
\hline $10 \mathrm{y}$ & - & - & 95.1 & $92.6-97.6$ \\
\hline $15 \mathrm{y}$ & - & - & 92.5 & $88-97$ \\
\hline $20 \mathrm{y}$ & - & - & 90.3 & $84-96.6$ \\
\hline \multicolumn{5}{|c|}{ Freedom from endocarditis } \\
\hline $1 \mathrm{y}$ & 98.1 & $96.5-99.7$ & 99.4 & $98.8-100$ \\
\hline $5 \mathrm{y}$ & 97 & $94.3-99.7$ & 98.9 & $97.9-99.9$ \\
\hline $10 \mathrm{y}$ & - & - & 98.9 & $97.9-99.9$ \\
\hline $15 \mathrm{y}$ & - & - & 98.9 & $97.9-99.9$ \\
\hline $20 \mathrm{y}$ & - & - & 98.9 & 97.9-99.9 \\
\hline
\end{tabular}

$C I$, Confidence interval; $O A T$, oral anticoagulation therapy.

the aortic graft. The majority of these patients had undergone previous operation in the ascending aorta or aortic root. However, this procedure is technically more complex because of the need to have the correct size and orientation of the graft between the coronary arteries to prevent late complications such as kinking of the limbs of the coronary Dacron graft and its occlusion resulting in AMI or sudden death. ${ }^{5,13}$

Hypothetically, the incorrect reimplantation of the coronary ostia could result in bleeding from coronary buttons, dissection, stretching, or torsion of the coronary arteries leading to wall motion abnormalities and the need for CABG. Moreover, the development of a pseudoaneurysm at the site of reimplantation of the coronary button is also rare but is possible. Byrne and colleagues ${ }^{14}$ reported a large series of root replacements, mostly with mechanical valve conduits, and showed that $2 \%$ of patients required $\mathrm{CABG}$ after coronary button reimplantation because of ventricular failure or bleeding from coronary ostia.

However, the incidence of myocardial infarction requiring $\mathrm{CABG}$ is comparable in the case of root replacement with stentless aortic root prosthesis. ${ }^{15}$

Another cardiac complication was heart block requiring pacemaker implantation, and this occurred in $1.8 \%$ of our population. CVG carried out according to the modified
Bentall technique is associated with a good long-term prognosis, especially for elective surgery. In our series, the overall long-term survival was satisfactory and was influenced by aortic dissection as the primary surgical indication. Patients with aortic dissection had a lower survival rate compared with those without aortic dissection $(39.7 \%$ vs $55.1 \%$ and $27.2 \%$ vs $43.3 \%$ at 15 and 20 years, respectively), with a statistically significant difference between the 2 groups $(P<.01)$. For elective surgery, the patients had a higher long-term survival rate than those operated on for aortic dissection. This highlights the practicality of performing surgery before aortic dissection occurs. The Bentall operation has proven to be the gold standard surgical treatment for patients affected by Marfan syndrome with aortic root aneurysm. With the introduction of the Bentall technique, the long-term survival of patients with Marfan syndrome has improved dramatically enough to be actually comparable with the general population. This procedure has a low operative mortality when carried out by experienced surgeons, with a long-term survival of around $80 \%$ at 5 years and $60 \%$ at 10 years. ${ }^{16}$

Gott and colleagues ${ }^{17}$ showed that, in patients with Marfan syndrome, elective aortic root replacement carries a significantly reduced morbidity and mortality compared with urgent and emergent operations. In a multicenter study with 675 patients, they reported an operative mortality rate of $1.5 \%, 2.6 \%$, and $11.7 \%$ for elective, urgent, and emergent procedures, respectively.

In our series, the survival rate of patients with Marfan syndrome was higher than for the other patients, with rates of $53.8 \%$ and $38.4 \%$, respectively, at 20 years. Because of the young age of these patients at the time of surgery, mechanical aortic valves needing life-long anticoagulation therapy are often used because of the risk of hemorrhage, thromboembolism, and prosthetic valve endocarditis. ${ }^{17}$ Valve-sparing aortic root replacement represents an attractive alternative option for patients with Marfan syndrome with normal or near-normal native aortic valves, because it avoids all the problems related to anticoagulation therapy. However, although the valve-preserving techniques have shown good results in mid- and long-term studies, ${ }^{18}$ the use of valve-preserving procedures is still debated in patients with Marfan syndrome. Fleischer and colleagues ${ }^{19}$ found histologic abnormalities in aortic valves from patients with Marfan syndrome, concluding that valvesparing procedures in these patients should be carefully re-examined in the light of these findings.

However, in 2011, Bernhardt and colleagues ${ }^{20}$ examined the results of the classic reimplantation technique according to the David procedure compared with the classic Bentall procedure in patients with Marfan syndrome. In both groups, the 30-day mortality was $0 \%$, while the long-term mortality was significantly higher for patients who underwent the Bentall procedure than for those in whom the 
aortic valve was reimplanted (10\% vs $3.4 \%$, respectively). In our institute, in the case of a perfectly intact and normally functioning tricuspid aortic valve, our tendency is to preserve it using the reimplantation technique according to the David procedure, especially in young patients. In the case of a normally functioning and clearly salvageable $\mathrm{BAV}$, which does not require any surgical repair, we try to preserve it. Otherwise our policy is to opt for the CVG, which is undoubtedly a more durable solution.

With regard to redo operations, overall freedom from proximal aortic reoperation was $93.8 \% \pm 1.3 \%$, $91.3 \% \pm 3.4 \%$, and $91.3 \% \pm 2.1 \%$ at 10,15 , and 20 years, respectively. The main causes of late reoperations include pseudoaneurysms of the coronary ostia anastomosis, or distal aortic anastomosis, paravalvular leak, and prosthetic valve endocarditis. In order to reduce the incidence of pseudoaneurysms of coronary ostia reimplantation, several changes have been made to the original technique. ${ }^{1,6,7} \mathrm{We}$ abandoned the original Bentall procedure in 1994, introducing the button technique. ${ }^{4-6}$

Since we initiated the button technique, the incidence of pseudoaneurysms has been significantly lower $(0.4 \%$ [4/ 926]) than when we used the classic Bentall operation (2.1\% [2/95]), and of the 33 aortic reoperations after the Bentall procedure, most were caused by distal aorta (aortic arch or descending aorta) disease (48.5\% [16 patients]), and some because of prosthetic valve endocarditis $(15.2 \%$ [5 patients]), prosthetic dysfunction (9.1\% [3 patients]), or dehiscence of the proximal or distal suture line $(9.1 \%$ [3 patients]), but only $18.2 \%$ (6 patients) because of pseudoaneurysm of the coronary ostia. However, we have had some cases of coronary artery pseudoaneurysm in patients in whom the coronary arteries were reimplanted using the button technique. In these extremely rare cases, the cause is more likely to be the extreme fragility of the tissues.

\section{Study Limitations}

Because of the retrospective nature of the study, the registration of the events over such a long period of time is suboptimal and underreported, especially because some of the follow-up was done by telephone.

The study was carried out over a long period of time, during which many factors related to surgical, anesthesiologic, and organ protection have changed and could not be accounted for using multivariate statistical analysis. Moreover, owing to incomplete data collection during the earlier years, some variables were not included in the statistical analysis. Therefore, the influence of these variables on early and late mortality could not be studied.

\section{CONCLUSIONS}

Aortic root replacement with CVG provides good early and long-term results. The coronary artery should be reimplanted using the button technique, and only when mobilization is ruled out should it be reimplanted with graft interposition. The incidence of valve-related complications is low; however, when complications occur they often lead to disability or death. Long-term care should include monitoring of the composite graft, the proximal and distal anastomosis, the reimplanted coronary arteries, and the remaining segments of the aorta.

\section{Conflict of Interest Statement}

Authors have nothing to disclose with regard to commercial support.

The authors thank the members of the Epidemiology and Biostatistics Unit Research and Innovation Department of the S Orsola-Malpighi University Hospital for their methodological and statistical support and contributions.

\section{References}

1. Bentall HH, de Bono A. A technique for complete replacement of the ascending aorta. Thorax. 1968;23:338-9.

2. Hagl C, Strauch JT, Spielvogel D, Galla JD, Lansman SL, Squitieri R, et al. Is the Bentall procedure for ascending aorta or aortic valve replacement the bes approach for long-term event-free survival? Ann Thorac Surg. 2003;76:698-703.

3. Pacini D, Ranocchi F, Angeli E, Settepani F, Pagliaro M, Martin-Suarez S, et al Aortic root replacement with composite valve graft. Ann Thorac Surg. 2003;76: 90-8.

4. Crawford ES, Svensson LG, Coselli JS, Safi HJ, Hess KR. Surgical treatment of aneurysm and/or dissection of the ascending aorta, transverse aortic arch, and ascending aorta and transverse aortic arch. Factors influencing survival in $717 \mathrm{pa}-$ tients. J Thorac Cardiovasc Surg. 1989;98:659-74.

5. Svensson LG, Crawford ES, Hess KR, Coselli JS, Safi HJ. Composite valve graf replacement of the proximal aorta: comparison of technique in 348 patients. Ann Thorac Surg. 1992;54:427-39.

6. Kouchoukos NT, Wareing TH, Murphy SF, Perillo JB. Sixteen-year experience with aortic root replacement. Results of 172 operations. Ann Surg. 1991;214: 308-20.

7. Cabrol C, Pavie A, Gandjbakhch I, Villemot JP, Guiraudon G, Laughlin L, et al. Complete replacement of the ascending aorta and reimplantation of the coronary arteries. New surgical approach. J Thorac Cardiovasc Surg. 1981;81:309-15.

8. Pacini D, Leone A, Di Marco L, Marsilli D, Sobaih F, Turci S, et al. Antegrade selective cerebral perfusion in thoracic aorta surgery: safety of moderate hypothermia. Eur J Cardiothorac Surg. 2007;31:618-22.

9. Etz CD, Bischoff MS, Bodian C, Roder F, Brenner R, Griepp RB, et al. The Bentall procedure: is it the gold standard? A series of 597 consecutive cases. J Thorac Cardiovasc Surg. 2010;140:564-70.

10. Gelsomino S, Frassani R, Da Col P, Morocutti G, Masullo G, Spedicato L, et al A long-term experience with the Cabrol root replacement technique for the management of ascending aortic aneurysms and dissections. Ann Thorac Surg. 2003;75:126-31

11. Knight J, Baumuller S, Kurtcuoglu V, Turina M, Turina J, Schurr U, et al. Longterm follow-up, computed tomography, and computational fluid dynamics of the Cabrol procedure. J Thorac Cardiovasc Surg. 2010;139:1602-8.

12. Patel D, Arteaga RB, Robinson VJ, Patel NA, Kapoor D. Angina, an unusual and late complication of the Cabrol procedure: a case report and review of the literature. Am J Med Sci. 2008;335:151-3.

13. Jault F, Nataf P, Rama A, Fontanel M, Vaissier E, Pavie A, et al. Chronic disease of the ascending aorta: surgical treatment and long-term results. J Thorac Cardiovasc Surg. 1994;108:747-54.

14. Byrne JG, Karavas AN, Leacche M, Unic D, Rawn JD, Couper GS, et al. Impac of concomitant coronary artery bypass grafting on hospital survival after aortic root replacement. Ann Thorac Surg. 2005;79:511-6.

15. Kincaid EH, Cordell R, Hammon JW, Adair SM, Kon ND. Coronary Insufficiency after stentless aortic root replacement: risk factors and solutions. Ann Thorac Surg. 2007;83:964-8.

16. Treasure T. Elective replacement of the aortic root in Marfan's syndrome. Br Heart J. 1993;69:101-3. 
17. Gott VL, Greene PS, Aleho DE, Cameron DE, Naftel DC, Miller DC, et al. Replacement of the aortic root in patients with Marfan's syndrome. $N$ Engl J Med. 1999;340:1307-13.

18. David TE, David CM, Manlhiot C, Crean AM, Bradley T. Outcomes of aortic valve sparing operations in Marfan syndrome. J Am Coll Cardiol. 2015;66:1445-53.

19. Fleischer KJ, Nousari HC, Anhalt GJ, Stone CD, Laschiner JC. Immuno-histochemical abnormalities of fibrillin in cardiovascular tissues in Marfan's syndrome. Ann Thorac Surg. 1997;63:1012-7.
20. Bernhardt AMJ, Treede H, Rybczynski M, Sheikzadeh S, Kersten JF, Meinertz T, et al. Comparison of aortic root replacement in patients with Marfan syndrome. Eur J Cardiothorac Surg. 2011;40:1052-7.

Key Words: aorta, aortic valve, Bentall procedure, composite valve graft

Readers who found these articles interesting may also like to read the following papers found in recent and future issues of our sister publications, Seminars in Thoracic and Cardiovascular Surgery and Operative Techniques in Thoracic and Cardiovascular Surgery!

\section{Acquired: Aortic Disease}

Original Submission: Outcomes of Open Surgical Repair for Type B Dissecting Aortic Aneurysm with Alternative Methods in the Endovascular Stent Era. Mitsumasa Hata. Semin Thorac Cardiovasc Surg 2015; Summer; 27(2):106-112.

Editorial Commentary: It is Difficult to Compare Apples and Oranges: Acute and Chronic Type B Aortic Dissections, Complicated and Uncomplicated, are Different and Should be Treated as Such. Ourania Preventza. Semin Thorac Cardiovasc Surg 2015; Summer; 27(2):113-114.

News and Views: Treatment of Thoracic Aortic Aneurysm: Role of Earlier Intervention. Bulat A. Ziganshin. Semin Thorac Cardiovasc Surg 2015; Summer; 27(2);135-143.

Aortic root enlargement during aortic valve replacement: Nicks and Manouguian techniques. Kendra J Grub. Oper Tech Thorac Cardiovasc Surg 2015; Autumn; 20(3):206-218.

The Konno-Rastan procedure for anterior aortic annular enlargement. Mark E. Roeser. Oper Tech Thorac Cardiovasc Surg 2015: Autumn; 20(3):219-233. 


\section{APPENDIX E1}

Variables Used in the Uni- and Multivariable Analyses for the Early and Late Mortality

Age $\geq 70$ years, gender, hypertension, history of smoking, hypercholesterolemia, diabetes, chronic renal insufficiency, coronary artery disease, chronic obstructive pulmonary disease, Marfan syndrome, BAV, dissection, reoperation, preoperative NYHA III-IV, operative periods 1978-1990/1991-2000/2001-2010, urgent/emergent status, CVG (modified Bentall, classic Bentall, Cabrol technique), $\mathrm{CABG}$, mitral valve replacement, $\mathrm{B}-\mathrm{CVG}$, and M-CVG. 